\title{
latrogenic brachiocephalic vein perforation during pacemaker implantation
}

\author{
Keisuke Nakabayashi
}

Department of Cardiology, Seirei Hamamatsu General Hospital, Hamamatsu, Shizuoka, Japan

\section{Correspondence to} Dr Keisuke Nakabayashi, keisuke2018@gmail.com

Accepted 14 January 2015

\section{DESCRIPTION}

An 82-year-old man with chronic obstructive pulmonary disease received a pacemaker implantation because of his advanced atrioventricular block. We smoothly inserted two sheaths by extrathoracic puncture into the left subclavian region. Mild resistance appeared at the proximal brachiocephalic vein (BCV). Venography revealed blood flow to the superior vena cava (figure 1A). However, we felt more resistance in the upper right atrium and could not propel two leads into the right atrium and right ventricle. Re-venography showed emigration of contrast into the anterior mediastinum (figure 1B). We diagnosed the patient with iatrogenic BCV perforation. His haemodynamics were stable; therefore, we pulled back the sheaths near the puncture sites and manipulated the ventricular lead into the right ventricular apex guided by pooled contrast. Instead of using an atrial lead, we implanted the VVI pacemaker to avoid expanding the perforation site.

Contrast-enhanced CT immediately after the procedure showed a haematoma and the pooled contrast in the anterior mediastinum (figure 2A, C); however, there was no haematoma growth following the delayed phase. We chose conservative therapy (ie, erythrocyte transfusion) and close monitoring. Follow-up CT confirmed no haematoma growth. The patient was discharged 7 days after the procedure.

From an anatomical viewpoint, the left BCV generally descends forward from the left and turns backwards in the middle of the anterior mediastinum. ${ }^{1}$ This case showed the strong tortuosity of the BCV (figure 2B). Therefore, knowledge of the anatomical characteristics of the left BCV is important, and the leads must be gently manipulated.

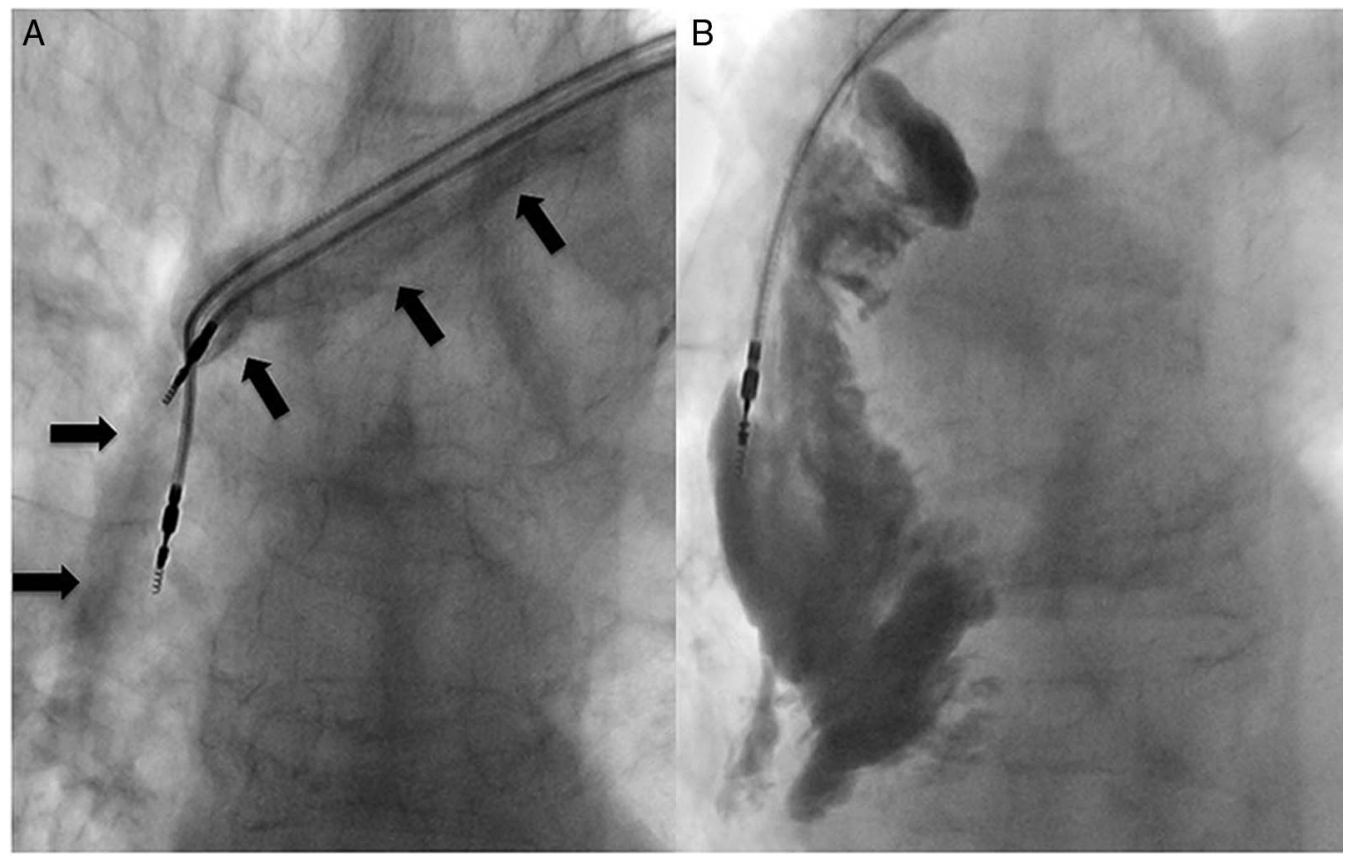

To cite: Nakabayashi $\mathrm{K}$. BMJ Case Rep Published online: [please include Day Month Year] doi:10.1136/ bcr-2015-209369
Figure 1 Venography during pacemaker implantation. (A) There is mild resistance, but the first venography showing a contrast stream from the left brachiocephalic vein to the superior vena cava (black arrow). (B) The second venography showing emigration of contrast to the anterior mediastinum from the left brachiocephalic vein to the upper right atrium. 
Figure 2 Contrast-enhanced CT. (A) Sagittal view. (B) Axial view of the yellow $B$ line. (C) Axial view of the yellow $C$ line. The white arrowhead indicates the pooled contrast. The red arrowhead indicates the strong tortuosity of the left brachiocephalic vein.

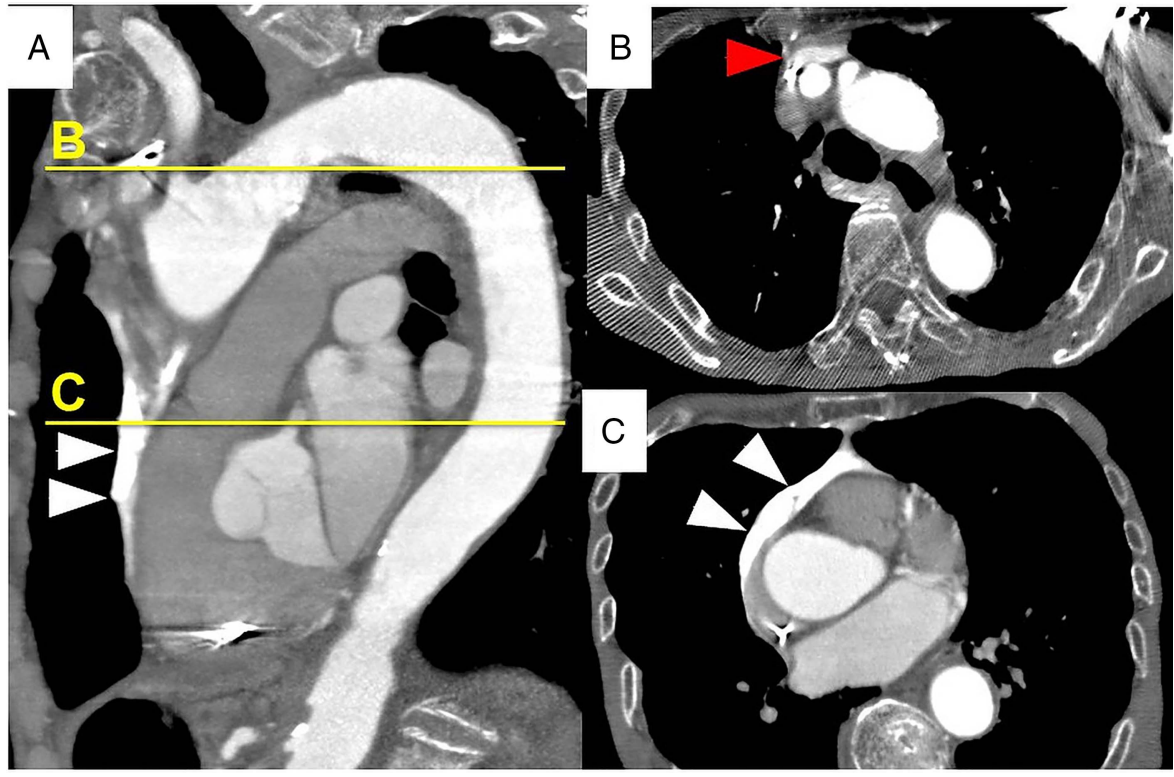

\section{Learning points}

- The left brachiocephalic vein is a common access for pacemaker implantation.

- latrogenic brachiocephalic vein perforation is a rare complication during pacemaker implantation, yet it is associated with life-threatening risks.

- Physicians must pay careful attention to the anatomica characteristics of the brachiocephalic vein, and gentle lead manipulation is necessary.
Competing interests None.

Patient consent Obtained.

Provenance and peer review Not commissioned; externally peer reviewed.

\section{REFERENCE}

1 Igawa $\mathrm{O}$, Adachi $\mathrm{M}$, Yano $\mathrm{A}$, et al. Brachiocephalic vein perforation on three-dimensional computed tomography. Europace 2007;9:74-5.

Copyright 2015 BMJ Publishing Group. All rights reserved. For permission to reuse any of this content visit http://group.bmi.com/group/rights-licensing/permissions.

BMJ Case Report Fellows may re-use this article for personal use and teaching without any further permission.

Become a Fellow of BMJ Case Reports today and you can:

- Submit as many cases as you like

- Enjoy fast sympathetic peer review and rapid publication of accepted articles

- Access all the published articles

- Re-use any of the published material for personal use and teaching without further permission

For information on Institutional Fellowships contact consortiasales@bmjgroup.com

Visit casereports.bmj.com for more articles like this and to become a Fellow 